\title{
COMUTAÇÃO AUTORAL E A PROBLEMÁTICA DA UNIDADE “AUTOR-OBRA" NOS QUADRINHOS
}

\author{
Lucas Piter Alves-Costa \\ Universidade Federal de Minas Gerais, MG
}

\begin{abstract}
Resumo
Este artigo tem por objetivo discutir a noção de Autor e Obra como correlatos e sua inserção em uma problemática da unidade entre essas noções, em uma perspectiva embasada em Foucault $(2008,2009)$. A partir de Maingueneau (2006) e Bourdieu (1996), os Quadrinhos são tomados, neste trabalho, como uma instituição relativamente autônoma que engendra um campo de atividades, o campo quadrinístico, no qual sujeitos posicionados como autores, mediadores e leitores atuam na elaboração, sustentação e legitimação dos nomes de Autores. A discussão sobre a unidade Autor-Obra se ampara na comutabilidade autoral presente nos Quadrinhos. A comutação autoral é o processo pelo qual as obras de quadrinhos são produzidas por diferentes autores, intercambiáveis entre si em outras obras e com papéis diversificados, tais como roteirista, desenhista, arte-finalista, colorista, entre outros. A discussão aponta para as dificuldades que há em definir o funcionamento da autoria (a função-autor) nos Quadrinhos devido à não-unidade entre Autor e Obra, característica dessa instituição.

Palavras-chave: Quadrinhos; Autoria; Nome de Autor; Michel Foucault.
\end{abstract}

\section{AUTHORIAL COMMUTATION AND THE PROBLEMATIC ABOUT THE UNIT “AUTHOR-WORK” IN THE COMICS}

\begin{abstract}
This article aims to discuss the notion of Author and Work as correlates and their insertion into a problematic of unity between these notions, in a perspective based on Foucault $(2008,2009)$. From Maingueneau (2006) and Bourdieu (1996), the Comics are taken, in this article, as a relatively autonomous institution that engenders a field of activities, the Comics field, in which agents positioned as authors, mediators and readers act in the elaboration, sustentation and legitimation of the Author's names. The discussion about the Author-Work unit is based on the author's commutability present in the Comics. Author's commutation is the process by which comics works are produced by different authors, interchangeable in
\end{abstract}

\footnotetext{
* Possui graduação em Letras pela Universidade Federal de Viçosa (UFV - 2011), mestrado em Letras pela Universidade Federal de Viçosa (UFV - 2013) e doutorado em Estudos Linguísticos pela Universidade Federal de Minas Gerais (UFMG - 2016), com estágio doutoral-sanduíche na Université Paris-Est Créteil (Paris XII UPEC), e Pós-doutorado no Programa de Pós-Graduação em Letras da Universidade Federal de Santa Maria (UFSM - 2017) com bolsa concedida pela Capes. Tem experiência na área de Letras, com ênfase em Letras/ Linguística, atuando principalmente nos seguintes temas: Linguística do Texto e do Discurso, Análise do Discurso, Semiolinguística, Língua Portuguesa, Literatura Brasileira, Narratologia (literária e quadrinística). Seu e-mail é alvescosta.lp@gmail.com.
} 
other works and with diverse roles, such as writer, artists, colorist, among others. The discussion points to the difficulties in defining the functioning of authorship (the author function) in the Comics due to the non-unity between Author and Work, characteristic of this institution.

Keywords: Comics; Authorship; Author's name; Michel Foucault.

\section{Considerações iniciais}

Este artigo parte de pressupostos sobre a autoria, mais especificamente, sobre a autoria nos Quadrinhos (COSTA, 2016). Considerados como a nona arte, os Quadrinhos são tomados, aqui, como uma instituição discursiva de relativa autonomia, tal como o são a Literatura ou o Cinema, e que instituem um campo discursivo - o campo quadrinístico -, com suas práticas, materialidades e sujeitos representativos dessa instituição.

A abordagem dos Quadrinhos como instituição se ampara nos pressupostos de Dominique Maingueneau (2006) desenvolvidos para a Literatura em sua obra Discurso Literário. A partir desse autor, podemos dizer que, similar ao que ocorre com a instituição discursiva literária, a instituição quadrinística incorpora: as práticas sociais da atividade dita quadrinística (tais como o processo de criação das obras, as sessões de autógrafos, as exposições e vendas de originais, a legislação sobre as obras, etc.); as materialidades características do meio quadrinístico (como as obras, histórias em quadrinhos, romances gráficos, tiras seriadas, sketchbooks, livros teóricos, galerias e livrarias especializadas, painéis publicitários, etc.); os agentes do campo quadrinístico (as posições sujeito que esses agentes ocupam, como autores, leitores e mediadores).

Abordar os Quadrinhos como instituição discursiva que engendra um campo de atividades próprio não significa considerar essa arte como um universo fechado em si mesmo e autossuficiente, constituinte de suas próprias leis de legitimação, de produção, circulação e recepção das obras sem levar em conta a estrutura social como um todo, inclusive da influência mercadológica. Essa visão romântica também foi criticada por Maingueneau (2006) em relação à Literatura, e a teoria do campo literário, proposta por Pierre Bourdieu (1996), e que também inspirou Maingueneau (2006), aponta na mesma direção. Maingueneau (2006), ponderando sobre a sociologia do campo literário bourdieusiana, diz que:

O conceito de instituição permite acentuar as complexas mediações nos termos das quais a literatura é instituída como prática relativamente autônoma. Os escritores produzem obras, mas escritores e obras são, num dado sentido, produzidos eles mesmos por todo um complexo institucional de práticas. (MAINGUENEAU, 2006, p. 53)

E mais adiante, já podemos transpor esse raciocínio sem muita dificuldade para o campo quadrinístico:

O conceito de instituição discursiva [quadrinística] articula: [1] as instituições, os quadros de diversas ordens que conferem sentido à enunciação 
singular: a estrutura do campo, o estatuto do [quadrinista], os gêneros de texto [...]; [2] o movimento mediante o qual o discurso se institui, ao instaurar progressivamente um certo mundo em seu enunciado e, ao mesmo tempo, legitimar a cena de enunciação e o posicionamento no campo que tornam possível esse enunciado. (MAINGUENEAU, 2006, p. 54)

O campo é um conjunto de relações com suas próprias regras, mas essas relações constitutivas e constituintes do campo são interpeladas em zonas limítrofes por práticas, materialidades e agentes de outros campos. No entanto, não é possível apreender os Quadrinhos, enquanto instituição, em sua totalidade. Da mesma forma que não o é possível fazer com a Literatura, o Cinema, a Ciência, etc. Por isso, a abordagem pelo viés do campo quadrinístico se faz pertinente e funciona como um recurso teórico-metodológico: o campo é, portanto, um conjunto de relações atrelado às instituições discursivas, no qual alguns de seus elementos constituintes são mais ou menos centrais, mais ou menos legitimados, dependendo do valor simbólico (e, por que não dizer, mercadológico) que lhe é atribuído ou da função (simbólica ou mercadológica) que esse elemento desempenha no campo. Esses valores e/ou funções relativas determinam a posição dos sujeitos no campo quadrinístico: autores e obras mais consagrados são mais centrais do que representantes amadores; da mesma forma, críticos e leitores especializados têm destaque e influenciam a lógica do campo, enquanto leitores consumidores tendem a ser influenciados; e, ainda, há agentes que ocupam posições intermediárias no campo, como livreiros, administradores, juristas, publicitários, cujos papéis não são centrais na instituição quadrinística, mas são fundamentais. Em qualquer dimensão de uma instituição, o campo é, como diria Bourdieu (1975), um lugar de lutas mais ou menos desiguais entre agentes desigualmente providos de capital simbólico.

O percurso teórico sobre a instituição quadrinística tem evidenciado que, assim como na Literatura, as práticas quadrinísticas são centradas na figura dos autores e das obras, não como indivíduos e textos empíricos, mas como entidades e produtos discursivos: ainda amparada em Maingueneau (2006), a abordagem dos Quadrinhos neste ponto do percurso teórico encontra Michel Foucault $(2008,2009)$ com seus questionamentos sobre as unidades discursivas impostas pelo nome do autor/Autor, pela concepção de obra/Obra, pela delimitação de áreas de conhecimento.

A problemática sobre a unidade Autor-Obra nos Quadrinhos que se pretende apresentar aqui nasce do diálogo com a Arqueologia do saber e O que é um autor?, de Foucault $(2008,2009)$. Tomando os Quadrinhos como instituição relativamente autônoma num cenário cultural mais amplo, podemos perguntar, com base nos pressupostos dessas obras: que diferenças específicas há entre essa instituição, como área do saber, e as outras; que dispositivos produzem essas diferenças; e o que elas mesmas fazem produzir? Não podemos ter a pretensão de responder a essas perguntas aqui. Nossa proposta é, antes, problematizá-las com foco nas noções de Autor e Obra, a partir, principalmente, de pressupostos de Foucault $(2008,2009)$, passando por considerações de Bourdieu (1996), corroborando e avançando, por fim, ideias de Maingueneau (2006), leitor de ambos. 


\section{Quadrinhos como discurso autorial}

As respostas para as perguntas da seção anterior trazem como centro a figura do autor, mais exatamente, da função-autor no interior de certas áreas de conhecimento, de certos domínios, de certas instituições discursivas. O nome de Autor, que não é tratado como um nome próprio qualquer, é indício de práticas muito específicas de um certo conjunto de discursos, e a existência de nomes de Autor diferencia tal discurso no interior de uma sociedade e de uma cultura. "Consequentemente, poder-se-ia dizer que há, em uma civilização como a nossa, um certo número de discursos que são providos da função 'autor', enquanto outros são dela desprovidos" (FOUCAULT, 2009, p. 274).

Que discursos seriam esses, que são providos da função-autor? Os processos de instauração da autoria nos Quadrinhos, e, por comparação, na Literatura, na Música, nas Artes, têm apontado que essas instituições contam com uma rede de dispositivos responsáveis por dar visibilidade, negativa ou positiva, aos autores e suas obras. Assim, a notoriedade de um autor não poderia ser tomada como fruto de um talento natural; antes, ela é construída no campo enquanto o próprio campo é, também ele, construído. Os elementos constitutivos do campo discursivo quadrinístico constituem as condições de produção dos Autores e das Obras ao mesmo tempo em que essas condições são elas mesmas produzidas. Nos mercados estadunidense e franco-belga, por exemplo, é comum encontrarmos livrarias especializadas em quadrinhos (comics, para o primeiro; bandes dessinées, para o segundo), bem como uma rede de publicidade para esses produtos, eventos temáticos e sessões de autógrafos como parte da promoção dos títulos e dos autores. Em resumo, a elaboração de espaços e estratégias de promoção da imagem do Autor consiste na produção das condições de produção dessa imagem; ou seja, as condições de produção do nome de Autor são também produzidas.

Assim, esses discursos que se diferenciam pela instauração da função-autor são chamados de discursos autoriais: aqueles discursos para os quais a função-autor é fundamental, ou seja, em que o nome de Autor é o centro de uma instituição, sendo ele construído de maneira coletiva por meio de uma rede de aparelhos e com base em um arquivo.

A formação da função-autor nos e por meio dos discursos autoriais permite estabelecer uma diferença entre autorial e autoral: os discursos autoriais produzem discursos autorais, mas a recíproca nem sempre é verdadeira. Isso quer dizer que os primeiros englobam não só os dizeres de Autores, mas também as práticas de uma dada instituição que possibilitam a existência deles; e também engloba os dizeres de não-autores, dizeres esses que têm por função (ou por efeito) sustentar os nomes de Autores. Já um discurso autoral, que está contido no primeiro, diz respeito àquele tipo de discurso no qual um sujeito se insere como o seu responsável e/ou o seu produtor efetivo, não ascendendo obrigatoriamente ao estatuto de Autor. Esse Autor, com maiúscula, mantém duas dimensões interdependentes: uma personificada (que diz respeito à persona do autor que ocupa a posição autor no campo) e uma enunciada (que diz respeito ao autor projetado, efeito do cam- 
po discursivo). Podemos resumir o raciocínio pela relação lógica: todo discurso autorial abrigaria discursos autorais, mas nem todo discurso autoral residiria em um discurso autorial.

A atividade propriamente autorial se distingue daquelas majoritariamente voltadas para a produção de textos efêmeros, que atendem a uma necessidade pontual, como alguns advindos do jornalismo, da política ou do ensino, por exemplo. Tais textos podem ter autores, com "a" minúsculo, mas não Autores, com " $\mathrm{A}$ " maiúsculo, pois não costumam ser coligidos para terem a função de Obras. $\mathrm{O}$ discurso autorial, portanto, se fundamenta pela construção coletiva de: (a) Autores, Obras e público, (b) um sistema de possibilidades de produção, circulação e recepção contínuas, (c) mediações (interdependentes) realizadas por um sem número de agentes não exclusivamente empenhados em atividades advindas de discursos autoriais. A atividade autorial, portanto, é sustentada por autores e não-autores, e não se limita a construir meros autores-produtores de textos.

\section{O (nome de) Autor como correlato da Obra}

O sentido dos nomes próprios está estreitamente ligado às diferentes ancoragens sociais dos discursos: histórica, geográfica, sociológica, literária e inúmeras outras (LECOLLE, PAVEAU, REBOUL-TOURÉ, 2009). O nome próprio tem, assim, uma função pontual, ele adquire sua força expressiva e utilitária quando relacionado a referentes bem marcados numa dada conjuntura. No caso do nome de Autor, ainda que seja um nome próprio, não é um nome de batismo, tampouco funciona como um.

Alguns nomes de Autor, como Jean Giraud ou Moebius, podem ter a mesma persona responsável por eles. De fato, Giraud se consagrou igualmente com os pseudônimos Gir e Moebius. Outro exemplo é o Autor Claude Guylouis, que nada mais é do que um pseudônimo composto pela persona de três autores: Claude Klotz, Jean-Louis Robert e Guy Vidal. Juntos, e sob a assinatura de Guylouis, foram autores de diversas histórias do personagem Lucky Luke. Guylouis também assinou com Emmanuel Boëm uma banda desenhada intitulada Sam et Léna (1992), pela editora Dargaud. Porém, Klotz já tinha um outro pseudônimo solo: Patrick Cauvin. Tanto Klotz quanto Cauvin tiveram uma produção autoral vasta, incluindo nela outras peças além de bandas desenhadas.

Ainda que o autor mantenha o seu nome de Autor o mais próximo possível de seu nome civil, o nome de Autor se tornará um pseudônimo à medida que a distância entre um antes e um depois do estado de autoria se intensificar. Neste ponto, não é simplesmente o nome que é falso, mas a pessoa de antes que não consegue mais portar o seu nome verdadeiro senão em condições sociodiscursivas muito específicas e muito restritas, ou até mesmo obrigatórias. Nos discursos autoriais, os nomes de Autor transcendem os seus portadores. Nesse contexto, a questão dos direitos autorais está centrada nas entidades empíricas que detêm esses direitos, mesmo que essa entidade (seja ela um sujeito ou uma editora) não exerça, de fato, a função-autor. É recorrente, no caso dos Quadrinhos, um nome de Autor ganhar notoriedade e funcionar como index de várias obras, enquanto 
os direitos autorais pertencem às editoras (Marvel e DC Comics são os exemplos mais representativos).

A convergência entre pseudônimo [ou nome de Autor] e discurso se opera via um simulacro de apagamento do sujeito. Se o pseudônimo [...] faz convergir referente e significado até se tornar um substituto do sujeito, não faria ele desaparecer esse último uma vez que ele se confunde com o discurso?1 (CISLARU, 2009, p. 56, tradução nossa)

Assim, o nome de Autor está além da persona do autor. Tratar o pseudônimo autoral em sua função discursiva nos Quadrinhos possibilita-nos visualizar a dimensão do Autor que não faz parte do dispositivo de comunicação como um indivíduo empírico criador de um discurso, e sim como um discurso produzido pelos dispositivos coletivos. Essa dimensão, a qual só é possível perceber por meio de uma cisão, é produto permanente desse dispositivo de linguagem que tem como horizonte o-homem-e-a-obra (FOUCAULT, 2008). O Autor seria, então, um efeito de sentido produzido nos e por meio dos discursos autoriais.

Ao enunciar sua obra, o autor enuncia o seu nome e em seu nome. Esse dizer é mais do que um falar sobre, é todo um enunciar e os aspectos pragmáticos que isso implicaria. Sua atividade de tomar a palavra não se trata de uma enunciação corriqueira, efêmera, mas uma enunciação que lega à posteridade enunciados sobre os quais e por meio dos quais toda uma categoria muito específica de discurso se funda - a dos discursos autoriais, que adquirem forma pela instauração progressiva de Autores e Obras. É desse modo que:

Fala e direito à fala se entrelaçam. De onde é possível vir legitimamente a fala, a quem pretende dirigir-se, sob qual modalidade, em que momento, em que lugar - eis aquilo a que nenhuma enunciação pode escapar. E o escritor sabe disso melhor do que qualquer pessoa, ele cujo discurso nunca acaba de estabelecer seu direito à existência, de justificar o injustificável de que procede e que ele alimenta desejando reduzi-lo. A obra só pode desenvolver seu mundo construindo nesse mesmo mundo a necessidade desse desenvolvimento. (MAINGUENEAU, 2006, p. 43)

De acordo com Alves-Costa e Lachovski (2018), o traço entre "o-homem-e-a -obra" encontrado em Foucault (2008) indicaria que a expressão não se trata, de um lado, do autor ou do homem, e do outro, do texto ou da obra, mas sim de uma simbiose dos dois, ou seja, não seria a mera união de dois elementos - "o sujeito que enuncia" e "a obra enunciada" -, mas sim um elemento outro, nem autor/ sujeito, nem obra/texto, mas que ainda assim aponta para ambos, para o portador do nome de Autor e para o produto de sua autoria. Os hifens, segundo os autores, denotariam uma só palavra, uma só coisa, substantivada, embora abstrata, e tal expressão conotaria um aspecto particular na produção de sentidos dos discursos autoriais: o nome de Autor seria um tipo de enunciado tão complexo que não permite notar a cisão entre autor e obra, pois, enquanto enunciado, seria, de fato, produzido no autor e na obra. Em l'homme-et-l'oeuvre, como no original, residiria 
essa ambiguidade necessária para a existência de Autores e Obras da maneira que se dá - um funcionamento muito menos problemático na Literatura, na Filosofia, e em discursos autoriais em que a coautoria é uma rara exceção, do que em discursos como a Música ou os Quadrinhos. (ALVES-COSTA; LACHOVSKI, 2018).

O nome de Autor tem uma função: ele não existe para dizer quem fala - não importa quem fala, diria Foucault (2008) -, ele não existe para especificar quem é a origem do enunciado, pois ele mesmo é um enunciado. Sua função, enquanto enunciado, e apesar de se confundir com o enunciador, é especificar a Obra e o sistema que a engendra.

Se podemos desenvolver hoje uma reflexão sobre a imagem de autor, é porque a encenação discursiva do escritor não é mais apreendida como um conjunto de atividades que permanecem no exterior do recinto sagrado do Texto, mas como uma dimensão inteirada ao mesmo tempo da comunicação literária como coenunciação e do discurso literário como uma atividade dentro de um determinado espaço social. Encontra-se a um nível de complexidade superior o princípio mesmo de uma "cena de enunciação" de obras [...]: enunciar em literatura não é somente configurar um mundo ficcional, é também configurar a cena de fala que é ao mesmo tempo a condição e o produto dessa fala.2 (MAINGUENEAU, 2009 , p. 3, tradução nossa)

A atribuição de autoria é, minimamente, o reconhecimento de uma atividade de empoderamento por parte de um sujeito, e o grau de relevância desse empoderamento depende de suas conjunturas sociodiscursivas: algumas dessas podem inscrever Autores e Obras (como nos discursos autoriais), e outras, apenas denotam os responsáveis por algo, os transgressores de algo, os autores de ' $n$ ', mas nunca o Autor.

Do ponto de vista jurídico, a redução ao efeito de responsabilidade pode parecer suficiente para explicar a autorialidade, mesmo das produções discursivas. Mas isso seria reduzir essa questão aos direitos autorais ou, no mínimo, forçaria a buscar a fonte real dos discursos. A observação de algumas práticas sociodiscurivas dos discursos de autoria tem revelado que não importa quem fala (se é Bakhtin ou Voloshinov, Homero ou a comunidade, a Marvel ou Jim Lee), nem quem detém os direitos sobre o que é falado (se é a DC Comics ou a Warner Bros), o nome de Autor foge a essas restrições e coerções (Kane e Finger são os Autores criadores de Batman, mas Frank Miller é o Autor do Batman: Cavaleiro das Trevas, que é o mesmo Batman, mas também é um Batman outro).

Uma vez que a problemática estabelecida por Foucault (2008) parte da premissa de que não importa quem fala, a compilação das obras desses autores pode se dar de duas maneiras: a primeira, e mais cômoda, seria compilar essa Obra a partir dos nomes de Autor, fazendo, assim, uma cisão entre o nome de Autor parecido com nome civil e os pseudônimos. A segunda, não tão cômoda, exigiria um esforço teórico: considerar o nome de Autor como parte da Obra, e assim sendo, a maior obra de um autor seria o seu próprio nome - um enunciado que transcende a materialidade/corporalidade de seus autores, enunciado esse no 
qual o autor investe sua trajetória no campo, seu Opus, seu ethos, para dar-lhe, enfim, existência maior. Enunciado esse no qual outros agentes no campo - a crítica, o público, os editores, os autores concorrentes - também investem, também corroboram. Essa segunda estratégia faria retornar ao nome de Autor original. Sua "genialidade" resumir-se-ia não só a "criar" gêneros textuais, mas toda uma discursividade amparada nos pseudônimos. Convém ressaltar que devemos usar o termo genialidade com precaução, ainda mais associado ao verbo criar, pois essa visão romântica dos autores é criticável.

Também pode ocorrer de um nome de Autor ser construído coletivamente por outros autores anônimos ou fantasmas - os chamados ghost writers -, como no caso de Maurício de Sousa, por exemplo. Por muito tempo, desde que o autor galgou sucesso e fundou a Maurício de Sousa Produções (MSP), os créditos de suas histórias foram atribuídos somente a ele. Mas no início do ano de 2015, diversos veículos de comunicação noticiaram que a MSP passaria a creditar os autores (desenhistas, roteiristas e arte-finalistas) no início de cada história, e não mais no final das revistas, na parte destinada à lista do expediente (e, portanto, sem especificar a autoria de cada história), devido a mudanças nas políticas editoriais do estúdio.

O caso de Maurício de Sousa é similar ao de Walt Disney, autor que também se valeu de uma equipe criadora que sustentava o seu nome: em ambos os casos, a atividade em torno do nome de Autor o fez se consolidar a tal ponto dele se tornar uma empresa - mais do que um Autor famoso, mas uma instituição em si. Na prática, já ocorria de longa data o fato de que não era mais a persona de Maurício de Souza que produzia suas histórias, e sim sua equipe. Uma avaliação panorâmica da carreira desse quadrinista nos permite notar como o seu nome de Autor se consolidou, tendo, inclusive, o próprio escritor/empresário se empenhado em estratégias de marketing e merchandising, como através dos produtos derivados de sua franquia ou dos inúmeros parques temáticos que sua empresa mantém.

\section{A comutabilidade autoral nos quadrinhos}

$\mathrm{Na}$ Literatura, um nome de Autor pode funcionar como ponto de partida para o conhecimento de outras obras. Sob um único nome, é possível encontrar 'n' obras. Nos Quadrinhos, como discurso autorial, também é possível percorrer uma trajetória marcada por títulos de obras a partir do nome de um Autor, que é a origem desse percurso. Mas, nos Quadrinhos, ao contrário do que é comum na Literatura, o caminho inverso também é possível, e com pontos de convergência muito variados: uma única obra, quando escrita em coautoria, também pode ser a origem de uma trajetória de encontro com diferentes autores. O sociólogo Luc Boltanski (1975), em sua abordagem da estrutura do campo quadrinístico, notou que os autores de banda desenhada

[...] publicam sob muitos pseudônimos diferentes, retomam séries desenhadas por outros produtores de quem adotam o estilo, compartilham 
com outros desenhistas a produção de uma mesma prancha (divisão do trabalho entre aquele que faz o esboço, a arte-finalização, a colorização ou, nos grandes estúdios, relativamente raros na Europa, como o estúdio Hergé, entre os especialistas de decoração, de personagens, de letragem, etc.).3 (BOLTANSKI, 1975, p. 38, tradução nossa)

Uma obra em quadrinhos pode apontar para uma trilha labiríntica de nomes de Autor compartilhados, de modo que a escolha por um ou outro desses nomes pode levar o leitor a universos ficcionais e textos tão variados em termos de estilo narrativo que a busca por uma unidade autoral, aos moldes da Literatura, se torna improdutiva.

$\mathrm{Na}$ Literatura existente a partir do advento do livro, e, em alguma medida e por uma abordagem retrospectiva, na Literatura anterior, criou-se a ilusão de se poder estabelecer a unidade da Obra - do Opus - de um Autor. Em Literatura, pode-se dizer "a Obra de Saramago" e, com isso, estabelecer abstratamente uma totalidade para um único nome, seguindo a noção de função-autor proposta por Foucault (2009). Mesmo que se encontrem na Literatura autores que escreveram ou só contos, ou só poemas, ou só romances, ou ainda autores que escreveram desses e doutros mais gêneros, os parâmetros para determinar a totalidade de uma Obra parecem ser aplicáveis a (quase) qualquer nome de Autor dentro do campo literário, pois tem sido esse o modus operandi da crítica literária, mesmo para nomes de autores distantes, em sua origem, da função-autor foucaultiana, como Homero e Shakespeare, por exemplo.

Mas, nos Quadrinhos, tal pretensão de totalidade enfrenta a problemática da autoria compósita, quase sempre explícita, que tende a ser a regra, e não a exceção. Ademais, essa autoria compósita é, por vezes, também comutativa, ou seja, os nomes de Autor são recombináveis entre si, formando uma rede de correlações. E, ainda, essa comutação implica determinação de papéis distintos, cujos principais tendem a ser o de desenhista e o de cenarista (ou roteirista), mas não são os únicos, nem tampouco exclusivos de cada autor. Moon e Bá, por exemplo, são desenhistas e roteiristas de suas histórias: esses papéis são revezados entre os dois. Enquanto autores consagrados como Alan Moore são famosos por serem somente roteiristas, deixando o desenho para diversos outros quadrinistas. Esse fenômeno pode ser chamado de comutação autoral (COSTA, 2016).

Em Matemática, a comutação é uma lei de combinação referente a elementos de um mesmo conjunto, cujo resultado não se altera se as posições de seus elementos são alteradas. Ao contrário da lei matemática, na comutatividade autoral, os elementos (autores) do conjunto (Quadrinhos) têm seus valores simbólicos alterados a depender de seus posicionamentos no campo e de seus lugares e relações de coautoria. Comutação autoral é, portanto, o processo pelo qual os nomes de Autor se associam dispersamente entre si em determinado campo, formando relações múltiplas de coautoria, e contribuindo, por isso, para tornar problemática a relação unitária entre (nome de) Autor e Obra.

Mesmo que a produção de uma história em quadrinhos seja, na grande maioria dos casos, um trabalho coletivo, os nomes que são comumente utili- 
zados como carro-chefe da obra são os do desenhista e do roteirista. The Sandman é canonicamente atribuído a Neil Gaiman, o roteirista, mas as 75 edições que compõem essa obra contam com mais de uma dezena de desenhistas e coloristas. Por sua vez, Jim Lee é desenhista, roteirista e arte-finalista4 de suas histórias. Fez incontáveis trabalhos sob a tutela da Marvel, da DC, da Image e da Wildstorm, editoras que detêm os direitos autorais de seus personagens independentemente de seus criadores, o que significa dizer que Lee roteirizou, desenhou e arte-finalizou histórias cujos personagens não foram suas criações. Dizer, por exemplo, "a Obra de Jim Lee" ou "a Obra de Neil Gaiman" é silenciar propositalmente a participação de ' $n$ ' roteiristas, desenhistas e coloristas que dividiram a autoria em ' $n$ ' títulos, ao menos do ponto de vista do trabalho com a linguagem quadrinística.

A história de Batman/Deathblow, por exemplo, é um crossover - cruzamento - de personagens de duas editoras diferentes: DC e Wildstorm. Ela foi produzida por oito quadrinistas (considerando roteirista, desenhista, arte-finalistas e coloristas), mas na capa da edição brasileira de colecionador (que compila os dois volumes dessa história) figuram somente seis nomes, divididos em três funções (roteiro, desenho, arte-final). Na capa, aparecem nesta ordem: Azzarello, Bermejo, Bradstreet, Frien, Guzman, Gray. Na página de rosto, onde se localizam os créditos gerais, os nomes aparecem nesta ordem e com os papéis atribuídos: Brian Azzarello (roteiro); Lee Bermejo (desenhos); Tim Bradstreet, Richard Frien, Lee Bermejo, Peter Guzman e Mick Gray (arte-final); Grant Goleash (cores); Raquel Arruda (letras); Fernando Bertarcchini (tradução e adaptação). Percebemos que na capa não aparece o nome do colorista.

Por sua vez, a edição brasileira de Wolverine Max: Fúria Permanente, pela Panini Comics, foi feita por oito quadrinistas, mas a capa omite dois dos três arte-finalistas (sendo que um desses é também o desenhista) e anuncia somente um dos três coloristas. Na capa, figuram os nomes Starr, Boschi, Ruiz, Brown, nessa ordem. Na página de rosto, os nomes aparecem na seguinte ordem com as atribuições: Jason Starr (roteiro); Roland Boschi e Feliz Ruiz (desenhos); Connor Willumsen, Craig Yeung e Feliz Ruiz (arte-final); Dan Brown, Andreas Mossa e Lee Loughridge (cores). Detalhe importante desta edição é que na folha de rosto a autoria dos desenhos, arte-final e cores é especificada por páginas, dividindo de maneira mais clara a responsabilidade por cada trabalho. Vê-se que a autoria nesta edição se manifesta de duas formas: na capa, os nomes consagrados de Autores que funcionam como índice de um grupo de obras - o Opus; na folha de rosto, os autores responsáveis, meros produtores com papéis específicos atribuídos por uma divisão do trabalho. 

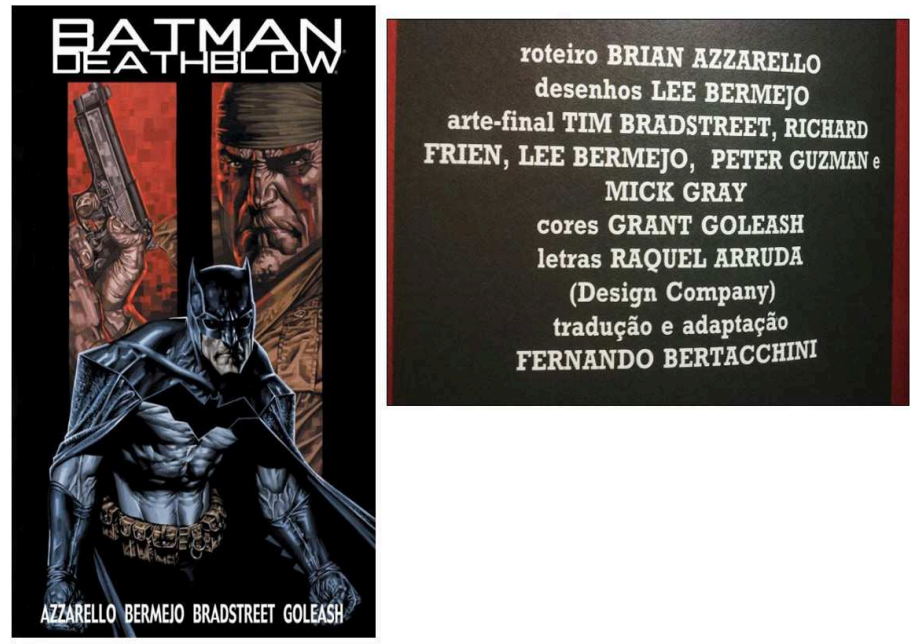

Figura 1: Créditos de Batman/Deathblow. Fonte: Arquivo pessoal

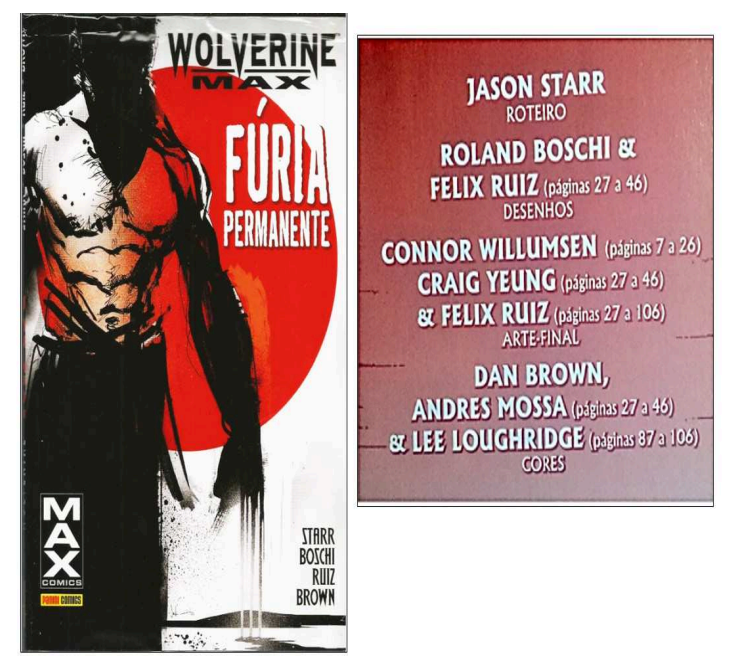

Figura 2: Créditos de Wolverine Max. Fonte: Arquivo pessoal

Vemos que não há critério regular para os créditos atribuídos nas capas de quadrinhos (que pode ser muito mais uma questão jurídica do que de valoração autoral), mas em geral, o crédito maior é dado para o roteirista e o desenhista. E os critérios para atribuição autoral (aqueles que buscam estabelecer a identidade concomitante de uma Obra e seu Autor) são igualmente nebulosos, fazendo parecer que essa convenção é fruto da mais proeminente subjetividade de um público.

A diferença de posicionamento existente entre os autores de Watchmen exemplifica bem como um nome de Autor pode ofuscar outro: Alan Moore é tido como o autor principal, uma vez que é notório que seus roteiros figuram entre os mais detalhistas do campo quadrinístico, deixando pouca liberdade criativa para Dave Gibbons, o desenhista, cujo nome também figura na capa. No entanto, pouco se fala de John Higgins, o colorista. O papel do colorista também é importante na criação da atmosfera da história e no direcionamento do modo como o leitor deve abordar a narrativa (uma vez que a cor afeta a leitura da 
narração, mas não a história narrada). Por meio das cores, trabalham-se luz, sombra, volume, clima, expressões emocionais etc. Vale comparar Watchmen com From Hell, obra que conta a história de Jack the Ripper (Jack, o estripador), também assinada por Moore, que é totalmente em preto e branco, com predominância do preto. Assim, por que considerar o colorista um autor menor ou simplesmente ignorá-lo se as cores são elementos tão importantes?

Nota-se que, nos Quadrinhos, o processo de comutação autoral faz com que a imagem do Autor escape às tentativas de unificação de uma identidade, privilegiando, assim, a diversificação dessa mesma identidade. Por comutação, a identidade enunciativa de cada Autor está sempre em transformação, pois ela é ressignificada pela identidade do(s) coautor(es).

Devido ao processo de comutação autoral (que é bem notável no campo quadrinístico, acadêmico, musical etc.), a identidade enunciativa de um autor, se quisermos com isso aludir a alguma impossível homogeneidade, fica visivelmente comprometida. O processo de comutação é, por essência, intersubjetivo, interenunciativo e interdiscursivo.

Logo, é possível encontrarmos Autores consagrados e, portanto, com maior capital simbólico, em coautoria com Autores menos conhecidos, que podem, por sua vez, ganhar visibilidade ou ser ofuscados em razão dessa coautoria. Do mesmo modo, o inverso também pode ocorrer: um Autor consagrado pode ter sua auctoritas comprometida se associado a Autores menores (alguns campos parecem ter regras rígidas em relação a isso, mas não parece ser, até o presente estudo, o caso do campo quadrinístico).

A coautoria, isso deve ser ressaltado, possivelmente não acrescentaria muitas questões à problemática da relação Autor-Obra se ela ocorre sempre entre os mesmos autores, pois o funcionamento dessa junção de nomes (a função-autor) seria o mesmo que o de um nome de Autor solo. Portanto, a comutação autoral não incide exatamente sobre qualquer autoria, mas sim sobre a variabilidade de coautoria a partir de um nome de Autor, que constitui a comutabilidade autoral.

A comutabilidade autoral é o conjunto de fatores que possibilitam a comutação. Talvez pudessemos indagar se a comutabilidade não deporia contra a autorialidade, o que apontaria uma direção para responder por que as reflexões sobre autoria são tão profícuas na Literatura e não o são em outros discursos autoriais, como os Quadrinhos. A discussão desse ponto não caberia aqui, como se vê, mas podemos supor que parece haver um maior investimento de capital simbólico em Obras correlatas de um só Autor, do que de coautoria.

\section{Apropriações e empréstimos, rupturas e dispersões}

Em Angoulême, durante o Festival Internacional de Banda Desenhada de 2015, as exposições de autores como Jack Kirby, Fabien Nury, Bill Watterson revelavam a dificuldade que é tentar definir "a Obra de..." por meio de um parâmetro aplicável a todos os nomes de Autor, como ocorre na Literatura. 
No caso de Kirby (pseudônimo de Jacob Kurtzberg), sua exposição foi organizada mais em função dos personagens que ele criou (muitos ao lado de Stan Lee ou Joe Simon) do que em obras unitárias ou séries. Intitulada Jack Kirby, le super-créateur, a exposição organizada cronologicamente evidenciava um autor cuja Obra escapa às tentativas de fechamento. Além do reconhecimento como criador de personagens icônicos na Marvel e DC, a exposição de Kirby ressaltou também, através dos painéis explicativos, o seu estilo peculiar de desenho.

No caso de Nury, que é cenarista/roteirista, sua exposição coligiu seus trabalhos em termos de títulos (séries e narrativas completas). Diferente de Kirby, cujo trabalho de suas próprias mãos é visível, o trabalho de Nury é visível pelos desenhos de diversos outros autores. O nome de Nury é um ponto comum que une desenhistas com estilos diferentes. Por fim, a exposição de Nury abre espaço para outros nomes que também têm outras obras.

Por um outro lado, a exposição de Watterson se restringiu à sua produção de Calvin \& Hobbes, que representa, em muitos sentidos, o mais próximo do que podemos dizer da totalidade de sua Obra. No entanto, Watterson trabalhou, antes de Calvin \& Hobbes, no jornal The Cincinnati Post com grande produção de charges e tiras políticas - obras que não são responsáveis, evidentemente, pelo index "Bill Watterson, autor de Calvin \& Hobbes". Essa fórmula funcionaria também ao inverso, "Calvin e Hobbes, autores de Bill Watterson", pois o Autor que se conhece hoje, e sobre o qual se fez uma exposição, só existe em razão de Calvin \& Hobbes: sua exposição em Angoulême marcava uma diferença entre o Watterson antes e depois desses personagens.

A constituição de uma obra completa ou de um opus supõe um certo número de escolhas difíceis de serem justificadas ou mesmo formuladas: será que basta juntar aos textos publicados pelo autor, os que ele planejava editar e que só permaneceram inacabados pelo fato de sua morte? Será preciso incluir, também, tudo que é rascunho, primeiro projeto, correções e rasuras dos livros? Será preciso reunir esboços abandonados? (FOUCAULT, 2008, p. 26)

Responder por uma obra ou se apropriar dela são operações que apontam para um indivíduo agente na instituição discursiva. Nesse ponto, não importa o estatuto desse indivíduo em relação à obra, se ele é, de fato, o produtor e/ou o signatário. Importa que haja um agente responsável pela circulação de discursos materializados em obras. Certamente que, no plano pragmático, a função-autor deve ser ancorada a um agente que, pleno de investimento de sentidos, faça-a funcionar. Mas a função-autor, como já dito, não está no indivíduo empírico: não importa quem fala.

Digamos que todo esse pragmatismo que faz funcionar a função-autor está no plano da enunciação, no plano do dizer e do fazer-dizer, do sentido a construir, o que explicaria a necessidade de sujeitos agentes. Mas no plano do enunciado, do dito, do sentido construído, o Autor é uma categoria desencarnada. Sua função não é mais a de responder por ou de se apropriar de. É, antes, uma função de indexar, de agregar sentidos e valores simbólicos. 
Como exemplo, podemos citar o caso de Bakhtin e Volóshinov que não é diferente do caso de Menard e Cervantes. A obra Marxismo e filosofia da linguagem (doravante MFL), por exemplo, antes atribuída a Bakhtin, mostra-se como pertencente a Volóshinov após as revelações do livro de Bronckart e Bota (2012). No entanto, podemos definir um campo semântico do MFL de Bakhtin e um do MFL de Volóshinov. Ainda que as duas obras sejam o mesmo texto, o fato de cada uma ser inserida num universo próprio de outras obras indexadas por cada nome de Autor dá a elas outros significados. Por muito tempo, MFL foi lido pela ótica bakhtiniana, o que obrigar-nos-ia a considerar a totalidade do pensamento desse autor e buscar interpretar concomitantemente cada obra sua pela leitura da outra. Com a instituição de Volóshinov como verdadeiro autor de MFL, a obra pode começar a ser lida dentro de um campo semântico diferente, próprio da unidade indexada pelo nome de Volóshinov. O nome de Autor, então, funciona também como ancoragem para os sentidos dos enunciados.

Em outros termos, a unidade material do volume não será uma unidade fraca, acessória, em relação à unidade discursiva a que ela dá apoio? Mas essa unidade discursiva, por sua vez, será homogênea e uniformemente aplicável? Um romance de Stendhal ou um romance de Dostoiévski não se individualizam como os de La comédie humaine; e estes, por sua vez, não se distinguem uns dos outros como Ulisses da Odisséia. É que as margens de um livro jamais são nítidas nem rigorosamente determinadas: além do título, das primeiras linhas e do ponto final, além de sua configuração interna e da forma que lhe dá autonomia, ele está preso em um sistema de remissões a outros livros, outros textos, outras frases: nó em uma rede. (FOUCAULT, 2008, p. 25-26)

O caso de Bakhtin/Volóshinov se insere na problemática estabelecida por Jorge Luis Borges em seu conto Pierre Menard: autor do Quixote. Essa mesma problemática foi trabalhada em relação a’O Alienista, de Moon e Bá, e, como se vê, ela pode se estender facilmente aos personagens criados por Kirby assumidos por outros autores, ou, ainda, a um sem número de nomes no campo quadrinístico.

No conto de Borges (2001), um narrador crítico literário fala da obra de Pierre Menard, um personagem escritor, em cujas obras estava o Quixote. Não o Quixote de Cervantes, mas o Quixote de Menard, embora o texto fosse exatamente o mesmo. No universo criado por Borges (2001), Menard havia escrito Dom Quixote, ipsis litteris, e Cervantes também.

Os casos elencados aqui impõem dificuldades não somente na constituição da unidade da Obra desses Autores, mas também na determinação da autoria, num sentido mais estrito. Quando não se sabe a delimitação de uma Obra, como determinar os seus limites em relação à autoria? Pode um sujeito se declarar autor de um enunciado outro, de um texto outro, já consagrado a outro Autor? Na ficção de Borges (2001), Menard quis escrever o Quixote e ser dele o Autor, da mesma forma que Cervantes é o Autor do Quixote, mas um Quixote outro. Menard, de fato, escrevera o Quixote. Palavra por palavra e linha por linha, mas sem reduzir a sua escrita a uma transcrição mecânica do original, sem fazer mera cópia. Aliás, o Quixote de Mernard não é o mesmo Quixote de Cervantes. 
O que teria feito, então, Menard? Uma explicação seria afirmar que ele compôs o Quixote pelo próprio Quixote, valendo-se de recursos da colagem e do silenciamento de algumas partes. $\mathrm{O}$ resultado foi um novo discurso, propenso a erradicar sentidos jamais cogitados pelo livro de Cervantes. Motivo: o sujeito da enunciação, a atitude enunciativa e o contexto de emergência do texto são outros. Portanto, a recepção acaba se condicionando por novas variáveis semióticas e espaço-temporais. (FERNANDES, 2007, p. 49)

O conceito de enunciação proposto por Benveniste (1989) é definido como um processo de apropriação; logo, o resultado desse processo ao ser materializado pode revelar traços dessa apropriação. Alguns traços são evidentes, outros, não. Mas a análise desses e de outros exemplos acabaria por evidenciar a heterogeneidade dos discursos. Tomemos o caso polêmico que ocorreu com as webtiras, da página La psicóloga honesta, do espanhol Molg H., que foram objeto de apropriação pelo brasileiro João Mirio Pavan, criador de uma página de Facebook, a Psicóloga Honesta. Diferente do fictício Pierre Menard, com o seu Quixote; e de Fábio Moon e Gabriel Bá, com o seu Alienista em quadrinhos, o sucesso de Pavan como Autor não durou muito. Porém, suas webtiras, sejam elas plágio ou não de Molg H., ocuparam um lugar no campo quadrinístico, ainda que periférico e sem legitimação de uma Obra.

\section{Considerações finais}

A autorialidade de cada instituição, ou seja, a forma como cada instituição lida com os seus autores e os textos daí produzidos, pode variar muito. É comum falarmos em Autores e Obras na Literatura, no Cinema, no Teatro, nos Quadrinhos, mas a maneira como a imagem desses Autores e o estatuto de Obra de seus textos são construídos é diferente, por razões diversas que não caberia discutir aqui.

O processo de comutação autoral é constitutivo dos Quadrinhos, embora não seja tão recorrente no mercado franco-belga como é no mercado norte-americano, para ficarmos só em dois exemplos. Esse processo é parte das condições de produção de algumas obras quadrinísticas. Se considerado em termos gerais, o seu efeito é fazer dispersar o nome do Autor, fazer a unidade desse nome sofrer dispersão, ruptura e apagamento no discurso quadrinístico. Por consequência, a própria noção de Obra sofre esse efeito.

Diz Foucault (2008) que a Obra não deve ser considerada como uma unidade imediata, nem uma unidade certa e homogênea. A Obra seria, então, uma dispersão? Se sim, a relação entre o nome do Autor e o estatuto de Obra como correlatos dispersos fica ainda mais evidente num discurso autorial como os Quadrinhos. Se a função-autor, como nos disse Foucault (2008), é uma forma de agrupar discursos dispersos sob um mesmo nome, funcionando, assim, como especificação de uma Obra, não seria o processo de comutação autoral nos Quadrinhos uma forma diferente de funcionamento da função-autor e, portanto, de especificação da Obra? 
Notas

1. La convergence entre pseudonyme et discours s'opère via un simulacre d'effacement du sujet. Si le pseudonyme [...] fait converger référent et signifié jusquà devenir un substitut du sujet, ne fait-il pas disparaître ce dernier lorsqu'il se confond avec le discours?

2. Si l'on peut développer aujourd'hui une réflexion sur l'image d'auteur, c'est que la mise en scène discursive de lécrivain n'est plus appréhendée comme un ensemble d'activités qui demeureraient à l'extérieur de l'enceinte sacrée du Texte, mais comme une dimension à part entière à la fois de la communication littéraire comme co-énonciation et du discours littéraire comme activité dans un espace social déterminé. On retrouve à un niveau de complexité supérieur le principe même d'une "scène d'énonciation " des œuvres [...] : énoncer en littérature, ce n'est pas seulement configurer un monde fictionnel, c'est aussi configurer la scène de parole qui est à la fois la condition et le produit de cette parole.

3. [...] ils publient sous plusieurs pseudonymes différents, reprennent des séries dessinées par d’autres producteurs dont ils adoptent le style, partagent avec d'autres dessinateurs la production d'une même planche (division du travail entre celui qui fait le crayonné, l'encrage, la couleur ou, dans les grands studios, relativement rares en Europe, comme le studio Hergé, entre les spécialistes des décors, des personnages, du lettrage, etc.).

4. Profissional responsável por aplicar a tinta (geralmente nanquim) nos esboços à lápis. Alguns desenhistas são também seus próprios arte-finalistas. Após a finalização, os desenhos são ainda coloridos, o que pode acontecer por um terceiro profissional. A contribuição de cada profissional é visível: um esboço carece de sombreado e pode apresentar imperfeições. É na arte-final que o sombreado principal é aplicado e as imperfeições corrigidas. Na parte de colorização é ainda possível acrescentar o efeito dégradé ao desenho, favorecendo volume e profundidade. O resultado final é fruto do trabalho de três profissionais.

\section{Referências}

ALVES-COSTA, L. P.; LACHOVSKI, M. A. Materialidades da autoria na sessão de autógrafos. Linguagem em (Dis)curso - LemD, Tubarão, SC, v. 18, n. 1, p. 147163, jan./abr. 2018. Disponível em: <http://www.portaldeperiodicos.unisul.br/ index.php/Linguagem_Discurso/article/view/6088/3639>. Acesso em: 11 abr. 2018.

AZZARELLO, B.; BERMEJO, L.; BRADSTREET, T.; GOLEASH, G. Batman/ Deathblow. Edição compilada. São Paulo: A\&C Editores, 2003.

BENVENISTE, E. Problemas de linguística geral II. Campinas: Pontes, 1989.

BOLTANSKI, L. La constitution du champ de la bande dessinée. In: ACTES DE LA RECHERCHE EN SCIENCES SOCIALES. Vol. 1, n 1, 1975, p. 37-59. Disponível em: <http://www.persee.fr/web/revues/home/prescript/article/arss_03355322_1975_num_1_1_2448>. Acesso em: 13 jun. 2015.

BORGES, J. L. Pierre Menard, autor do Quixote. In: BORGES, J. L. Ficçães. São Paulo: Globo, 2001, p. 53-63.

BOURDIEU, P. La spécificité du champ scientifique et les conditions sociales du progrès de la raison. Sociologie et société, vol. 7, n. 1, 1975, p. 91-118. Disponível em: <https://www.erudit.org/revue/socsoc/1975/v7/n1/001089ar.pdf>. Acesso em: 16 jan. 2016.

As regras da arte: gênese e estrutura do campo literário. Trad. Maria Lucia Machado. São Paulo: Companhia das Letras, 1996. 
BRONCKART, J.-P.; BOTA, C. Bakhtin desmascarado: história de um mentiroso, de uma fraude, de um delírio coletivo. Trad. Marcos Marcionilo. São Paulo: Parábola, 2012.

CISLARU, G. Le pseudonyme, nom ou discours ? D'Etienne Platon à Oxyhre. In: LECOLLE, M.; PAVEAU, M.-A.; REBOUL-TOURÉ, S. Les carnets du Cediscor: le nom propre en discours, n.11. Paris: PSN, 2009, p. 39-57.

COSTA, L. P. A. Uma análise do discurso quadrinístico: práticas institucionais e interdiscurso. 2016. 223 f. Tese (Doutorado). Programa de Pós-Graduação em Estudos Linguísticos, Universidade Federal de Minas Gerais, Belo Horizonte, Minas Gerais, 2016.

FERNANDES, C. A. A noção de enunciado em Foucault e sua atualidade na análise do discurso. In: FERNANDES, C. A.; SANTOS, J. B. dos. (Orgs.). Percursos da análise do discurso no Brasil. São Paulo: Claraluz, 2007, p. 49-68.

FOUCAULT, M. A arqueologia do saber. Trad. Luiz Felipe Baeta Neves. Rio de Janeiro: Forense Universitária, 2008.

FOUCAULT, M. O que é um autor?. In: FOUCAULT, M. Estética: literatura e pintura, música e cinema. Org. Manoel Barros da Motta. Trad. Inês Autran Dourado Barbosa. Rio de Janeiro: Forense Universitária, 2009, p. 264-298.

GAIMAN, N. [et al.]. The Sandman: absolute V. 1 New York: DC Comics, 2006.

GUYLOUIS, C.; BOËM, E. Sam et Léna. Tome 1. Paris: Dargaud, 1992.

LECOLLE, M.; PAVEAU, M.-A.; REBOUL-TOURÉ, S. Les sens des noms propres en discours. In : LECOLLE, M.; PAVEAU, M.-A.; REBOUL-TOURÉ, S. (Orgs). Le nom propre en discours. Les carnets du Cediscor, 11, 2009. Paris : PSN, 2009, p. 9-22.

MAINGUENEAU, D. Discurso literário. São Paulo: Contexto, 2006.

. Auteur et image d'auteur en analyse du discours. Argumentation et Analyse du Discours [On line], 3, 2009, p. 1-14. Disponível em: <http://aad.revues. org/660>. Acesso em: 01 dez. 2012.

MILLER, F. Batman: cavaleiro das trevas. São Paulo: Panini, 2011.

MOON, F.; BÁ, G. O alienista. Adaptação em quadrinhos. São Paulo: Agir, 2007.

MOORE, A.; GIBBONS, D.; HIGGINS, J. Watchmen: the absolute edition. New York: DC Comics, 2008.

STARR, J.; BOSCHI, R.; RUIZ, F.; BROWN, D. Wolverine max: fúria permanente. São Paulo: Panini, 2013. 